International Journal of Current Advanced Research

ISSN: O: 2319-6475, ISSN: P: 2319 - 6505, Impact Factor: SJIF: 5.995

Available Online at www.journalijcar.org

Volume 6; Issue 5; May 2017; Page No. 3758-3762

DOI: http://dx.doi.org/10.24327/ijcar.2017.3762.0363

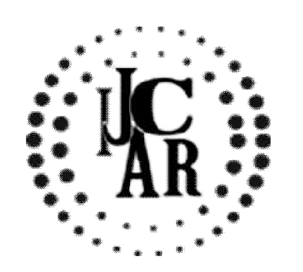

Research Article

\title{
IMMUNOLOGY OF INFECTIONS AT THE PRESENT STAGE.BIOLOGICAL RHYTHMS OF IMMUNE REACTIVITY
}

\author{
AM Zemskov ${ }^{1}$., IE Esaulenko', VM Zemskov*2., VA Zemskova1., \\ OA Popova ${ }^{1}$., YaV Kulintsova ${ }^{1}$ and VS Demidova ${ }^{2}$
}

${ }^{1}$ Burdenko Voronezh State Medical University, Voronezh, Russia

${ }^{2}$ Vishnevsky Institute of Surgery, Moscow, Russia

\begin{tabular}{|c|c|}
\hline 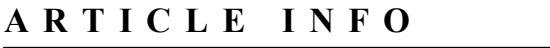 & A B S T R A C T \\
\hline Article History: & It is shown that in the current conditions of the aggressive external environment, including \\
\hline $\begin{array}{l}\text { Received } 20^{\text {th }} \text { February, } 2017 \\
\text { Received in revised form } 12^{\text {th }} \text { March, } 2017 \\
\text { Accepted } 15^{\text {th }} \text { April, } 2017 \\
\text { Published online } 28^{\text {th }} \text { May, } 2017\end{array}$ & $\begin{array}{l}\text { the traumatic effects of medical diagnostic and treatment technologies, there are significant } \\
\text { changes in immune reactivity and its biological rhythms, which is accompanied by a } \\
\text { modification of the etiology, pathogenesis and clinical features of infections that hamper } \\
\text { their detection and treatment. }\end{array}$ \\
\hline
\end{tabular}

Key words:

Infection, Immunity, Biorhythms.

Copyright $(2017$ AM Zemskov et al. This is an open access article distributed under the Creative Commons Attribution License, which permits unrestricted use, distribution, and reproduction in any medium, provided the original work is properly cited.

\section{INTRODUCTION}

\section{Features Of The Infections Cause At The Present Stage}

The objective reality today is an increased risk of development, a change in the spectrum, etiology and pathogenesis, clinical course, laboratory diagnosis, treatment and prevention of infectious diseases. According to the laws of biology and genetics, representatives of the microworld also evolve, as do representatives of other species of living beings. Over the past 20-30 years, more than three dozen new and mutated microorganisms have been discovered. All of them are united in a group of emergent, dangerous infections for a person $[1,2,3]$.

Thus, human immunodeficiency viruses (HIV), hemorrhagic fevers (Marburg, Lassa, Ebola), pathogenic bacteria and viruses that cause atypical pneumonia, Legionnaires' disease, Lyme fever have been discovered. Some well-known microorganisms have acquired pathogenic properties and become dangerous for humans - the monkeypox virus, Helicobacter pylori, which causes peptic ulcer of the stomach and duodenum, etc. Parenteral hepatitis, tuberculosis, and chlamydia have become epidemic. Close to this is the spread of the viral syndrome, chronic fatigue syndrome, etc. The frequency of infection of the female genital organs with

*Corresponding author: VM Zemskov

Vishnevsky Institute of Surgery, Moscow, Russia mycoplasmas, gardnerella, chlamydia and other intracellular parasites has increased. In general, the incidence of viral infections (measles, hepatitis, rabies, Dengue fever, yellow fever), bacterial (plague, cholera, tuberculosis, diphtheria, whooping cough, typhoid fever), parasitic (malaria, toxoplasmosis, echinococcosis) infections has increased. Thanks to the global vaccination, smallpox, prickly heat, and some other infections completely disappeared. This violates the balance of microorganisms that has developed over hundreds of millions of years, which can have unpredictable consequences for mankind, animals, and plants. An example of this is the increasing role in human pathology of T-cell leukemia viruses, hepatitis, oncoviruses, prions, causing bovine rabies, modified influenza pathogens, etc $[4,5]$.

These patterns led to a negative epidemic forecast for the $21 \mathrm{st}$ century, which is determined by the following positions: (1) the emergence of absolutely "new" pathogens of infectious diseases (Ebola fever, HIV, HCV infection, atypical pneumonia - SARS); (2) activation or "return" of old infections is possible. In Japan, the vaccination against pertussis was stopped in the 1970 s, which resulted in the epidemic of this infection. As a result of the reduction in vaccination companies in 2000, there was an outbreak of polio in Chechnya, and measles in Hungary and Colombia. The migration of known (controlled) pathogens to "new" territories is expanding. In 1999, 4,000 people were infected with the West Nile virus in the United States due to migrants from Africa. It is necessary to modify the vaccination strategy in new epidemic conditions, paying attention to (1) preventing 
the return of "old" infections due to mass vaccinations of children even in the absence of morbidity; (2) creation of vaccines against "new" pathogens "on the basis of the global system of early detection of unknown infectious agents using genetic engineering technologies; (3) use of immunomodulators and monoclonal antibodies for the earliest prevention of "new" infections [6].

\section{General characteristics of the course of infections at the present stage}

They are: 1.Change of etiological factors - acute diseases (smallpox, plague) give way to pathological processes caused by intracellular parasites (viruses, chlamydias), including slow infections (AIDS), especially dangerous for children, the elderly, pregnant women, chronic patients. 2. Expansion of the spectrum of infectious diseases. Participation of infectious agents in somatic diseases is proved: cervical cancer papillomavirus, herpes of type 1,2; Burkitt's lymphoma, nasopharyngeal carcinoma - Epstein-Barr virus, primary liver cancer - viral hepatitis B, C; cellular lymphosarcoma lymphotropic viruses BVI and BII, peptic ulcer, duodenal ulcer - Helicobacter; Crohn's disease - Yersinia enterocolitis, rheumatic carditis - Coxsackie viruses A13, A18, B1, B2, B3, streptococcus; ischemic heart disease - possibly chlamydia. There is a well-founded opinion that chronic infections (caused by chlamydia, etc.) are the cause of atherosclerosis, Alzheimer's disease, diabetes, stroke, infertility, multiple sclerosis. At the same time, $15-20 \%$ of cases of human malignant tumors are of an infectious nature. At the same time, it is possible to exclude the infectious origin of many tumors only in 5 cases out of 100 . In addition, it is possible to assume the infectious nature of schizophrenia, since children with this pathology are born more often at the end of winter and early spring, when the greatest peak of prenatal or neonatal infections is noted.

Moreover, $42 \%$ of patients with schizophrenia show positive reactions to Toxoplasma gondii, and among healthy ones, only $11 \%$. 3. The formation of positive pathomorphosis mitigating the nature of the course of diseases, in the form of inpatient clinical forms in combination with frequent early or late recurrence of pathological processes (typhus, salmonellosis, brucellosis, tularemia, tuberculosis, malaria, herpes, Q-fever, ornithosis, etc.). There is also frequent formation of secondary complications, asymptomatic carriage, persistence of infections, dysbiosis, immune disorders. 4. Due to the use of vaccinations, especially live agents, passive immunization, the use of antibiotics, other bacteriostatic, bactericidal, chemical, hormonal drugs, bacteriophages, immunosuppressors and others, induction of adaptive (ecological) variability of microorganisms, transformation of zooantroponosis (plague, yellow fever, salmonellosis) in human anthroponosis, change in the typical location of pathogens, for example a pyocyanic bacterium from an intestine in other organs with development of empyemas of a pleura, arthritises, coloenterites, sepsis, prevalence of an ornithogenic way of pathogens circulation (bird flu), etc. 5 . Variability of causative microorganisms due to the modification of the enzyme spectrum, which is manifested by the appearance of new invasive factors, changes in the saccharolytic and other properties (difficulty in diagnosis), the formation of shigopodal exotoxins (diarrhea), the presence of L-forms, the predominance of conventional prevalence of conditional and low-pathogenic microflora, mixinfection, a polyvalent antibiotic resistance, autoinfection, causing difficulty of treatment $[7,8]$.

\section{Causes of changes in the course of infections}

These include: 1. Evolutionary unpreparedness of a person for the scientific and technological revolution (creation of new environmental factors - radioactive background, chemical pollution, accumulation of $\mathrm{CO}_{2}$, etc.). 2. Decrease in the quality of life of the population (low birth rate, incomplete offspring, chronic diseases, drug addiction, alcoholism, etc.). 3. Defective food (genetically engineered products, reduced sanitary and hygienic standards, starvation, beriberi). 4. Twofold aging of the population (with the need for frequent treatment, diagnosis). Development of malignant neoplasms, age-related wilt of the immune system. 5. Spasticity of patients. In the Russian Federation, 3 million 300 thousand beds are located on the total area $-15-16 \mathrm{~km}^{2}$, where for 1.2 billion days there are 64 million patients and 6 million health workers. 6. Strengthening migration processes (refugees, "sexturism" with the rapid spread of pathogens from endemic foci). 7. Diagnostic, therapeutic aggression. There are more than 3000 types of various interventions (catheterization, broncho-, gastroscopy, artificial blood circulation apparatus, anesthesia apparatus, etc.) that cause violation of mechanical barriers, change the biocenosis of the skin and mucous membranes, contribute to contamination with antibiotic resistant strains of pathogens. 8. "Prosthetics" of the population immune system with vaccines (in Russia, about 150-200 million people annually undergo active and passive immunization and therapy), which may lead to a negative vaccine phase in some people (within 10-14 days suppression of anti-infective protection) and development vaccination reactions, defective vaccinal immunity, etc. $[9,10,11,12]$.

\section{The Role Of Immunoaggressive Environmental Factors}

The immune system is highly sensitive to environmental changes. Therefore, the study of immune reactivity is advisable to carry out at a stage when the inducing factors have not yet led to the development of diseases, but have already caused immune damage. It is clear that the stability of the immune system to negative influences on the body depends on the genotype, health status and much more. Nevertheless, the general patterns of reaction exist under these conditions. The sensitivity of individual links of the immune system to any factors is different, but in any case it is a critical target for a large number of eubiotics and other effects. This circumstance determines the formation in the organism of donosological changes in immune reactivity, which, on the one hand, are markers of the disadvantage of the habitat conditions, and on the other hand provide the basis for the subsequent development of pathology, chronization or weighting of existing diseases [13].

The following types of reactions of the organism to the influence of immunotropic ecofactors are distinguished: 1 . Increased reactivity and the possibility of allergies and autoimmune diseases development. 2. Suppression of reactivity and the possibility of immunodeficiency states of type 2 and cancer development. 3. Lymphoproliferative processes and the possibility of leukemia development.

\section{Chemical substances}

To date, the number of chemicals is estimated at 4 billion (63 thousand are used in everyday life), causing various immune 
disorders. These substances are divided into the following groups. 1. Products of complete or partial combustion of fossil fuels - fly ash, toxic radicals, nitrogen peroxide, sulfur dioxide, polycyclic aromatic hydrocarbons, benzopyrenes, cholanthrenes. 2. Products of the chemical industry: benzene, phenols, xylene, ammonia, formaldehyde, products of plastics, rubber, paint and varnish industry, oil products. 3 . Products of household and agricultural chemistry, pesticides, insecticides, herbicides, fertilizers, detergents, cosmetics, medicines, flavors etc. 4. Metals: lead, mercury, cobalt, molybdenum, etc. 5. Inorganic dust, quartz dioxide, asbestos, carbon, talc, polymetallic aerosols, welding aerosol, etc. 6 . Biological pollutants, plant pollen allergens, microscopic mites, fungi, viruses, bacteria, parasites, etc.

Mechanisms of damage to the immune system are diverse. For example, chlorinated cyclic dilexines, brominated biphenyls, methylmercury cause CD3 lymphocyte maturation, thymic atrophy, and lymph node hypoplasia; alkylating compounds, benzene, ozone, heavy metals cause immunosupression due to DNA damage, and aromatic amines, hydrazine cause the formation of cytotoxic antibodies and cell populations against autolymphocytes. The use of halogen aromatic compounds, ozone is accompanied by a decrease in the production of interleukins and interferons; chlorinated cyclic dilexines - subpopulations of CD19lymphocytes and the formation of antibodies; heavy metals, acridine dyes, hexachlorobenzene, aromatic amines complement defects with a risk of developing the system of lupus erythematosus.

\section{Irradiation with ionizing radiation}

The wide spread of nuclear technology entails the expansion of the number of persons exposed to adverse effects of radiation factors, which is accompanied by the development of pathological processes.

Increase in permeability. Irradiation of the body increases the permeability of the skin, subcutaneous fat, pulmonary, bloodbrain and hemato-ophthalmic barriers, intestinal vessels in relation to various microorganisms, decay products of autotissues, etc. These processes contribute to the development of complications.

Anti-infective resistance. A common characteristic feature of the irradiated organism is the lengthening of the periods of purification from pathogens, the propensity to generalized infections, and the resistance to opportunistic microorganisms (Escherichia coli, proteus, sarcin, etc.) is especially reduced. Oppressive resistance to bacterial toxins of $\mathrm{Cl}$. Perfringens, Cl. Tetani, Cl. Botulinum, diphtheria bacillus, staphylococcus, Shigella. This is based on a decrease in the ability of blood serum to neutralize toxins, as well as damage to the hypophysis, adrenal, thyroid glands function.

Influence on the microflora. Representatives of normal automicroflora, living in natural cavities, as well as pathogens, located in different foci of infection, migrate into the blood, spread to organs. At the same time, the composition of normal microflora sharply changes, the content of lactic acid bacteria decreases, and the number of intestinal bacilli and pseudomonas aeruginosa increases. However, species immunity is highly stable to the influence of ionizing radiation.
Influence on Immunity. In relation to specific immunity, irradiation with lethal and sublethal doses of radiation before immunization causes within the first two days a sharp suppression of the formation of antibodies, which is held up to 7 days or more. The inhibition of antibody formation is combined with a significant elongation of the inductive phase of antibody genesis from 2-3 days in normal, up to 11-18 days. As a result, the maximum production of antibodies is registered only after 40-50 days after irradiation.

Two phases of antibody genesis were established under the action of ionizing radiation. The first is radiosensitive, lasting 1-3 days, the second is radioresistant, which is the rest of the time. Revaccination is effective enough for primary immunization, performed before irradiation. Chronic irradiation at the same dose as acute applied before vaccination, to a much lesser degree damages immunity. Most of the lymphocytes are highly sensitive to radiation, and this is already manifested when exposed to external radiation at a dose of 0.5 to 10.0 Gray. Cortical thymocytes, spleen $\mathrm{T}$ cells and B-lymphocytes are most sensitive to the effect. CD4lymphocytes and T-killers are more stable. Changes in the humoral immune link were less pronounced. Small doses of radiation, as a rule, do not cause gross morphological changes in the immune system. Their effect is realized mainly at the level of functional disorders, the recovery of which is very slow and cyclical. In a number of cases, even after 2 years, the preservation of the secondary immunodeficiency state was noted. In addition to the negative effect of the radiation factor on lymphocytes, damage of the immune system auxiliary cells occurs. In particular, stroma and epithelial cells of the thymus is affected, which leads to a decrease in the production of thymosin and other thymic factors. As a result, sometimes even in 5 years there is a decrease in the cellularity of the thymus cortex, a disorder of T-cell synthesis, the function of the peripheral organs of the lymphoid system is weakened, and the number of circulating lymphocytes is reduced. At the same time, antibodies are formed against the thymus tissue, which contributes to the "radiation aging" of the immune system. There is also an increase in the synthesis of $\operatorname{IgE}$, which increases the risk of allergic and autoimmune processes in the irradiated organism.

\section{Other factors}

Electromagnetic waves and microwave fields in chronic exposure cause phase fluctuations in the phagocytic activity of neutrophils, a violation of the antibodies synthesis, which causes the development of immunopathological and immunosuppressive states.

Noise with an intensity of 60-90 decibels for 2 months or more contributes to the suppression of bactericidal and complementary activity of blood serum, a decrease in the titers of normal and specific antibodies.

Different metals have a significant effect on the immune system. Beryllium, vanadium and iron induce, respectively, (1) sensitization and immunomodulation, (2) stimulation of lymphoproliferation and immunomodulation, (3) oppression of phagocytosis and antibody formation; Gold, cadmium, potassium and cobalt - (1) suppression of chemotaxis and release of enzymes from phagocytes, (2) inhibition of the humoral immune response, (3) CD3-lymphopenia, (4) decreased delayed type hypersensitivity and NK cell activity, (5) Induction of delayed and immediate hypersensitivity. 
Selenium and zinc can cause modulation, hypoplasia of the thymus, development of immunodeficiencies.

Malnutrition indicates that moderate manifestations of it do not cause profound damage to immune reactivity. However, in chronic protein-caloric deficiency, a decrease in the activity of phagocytosis, the properdin-complementary system, the formation of interferon, lysozyme, immunoglobulins of various classes, a decrease in the content of CD3 and CD19 lymphocytes and their subpopulations, an increase in the number of immature null cells. Deficiency of retinol, riboflavin, folic acid, pyridoxine, ascorbic acid, iron reduces the resistance of tissue barriers, and in combination with lack of protein inhibits the activity of cellular and humoral immunity. In people with hypovitaminosis, infectious diseases occur more often, severe, are prone to chronic diseases and complications. Exclusion of animal proteins from the diet causes inhibition of humoral defense mechanisms, a nucleic acids, even with sufficient caloric intake - inhibition of cellular immunity. It should be emphasized that fasting, including healing, to some extent reproduces the above effects.

\section{Physiological Changes In Immune Reactivity}

Constant adaptive changes in immune reactivity are the main survival of the organism in an ever-changing external world. In different periods of life (childhood, old age, during pregnancy) and in other cases, there are significant variations in the expression of immune mechanisms (activation of some, suppression of other links), which are physiological reactions of adaptation, and not evidence of the formation of any pathological processes.

\section{Daily circadian vibrations}

Known similar fluctuations in parameters of nonspecific antiinfective resistance. The highest indices of phagocytosis and properdin were found during day and night, the lowest at night and in the morning. The maximum content of lymphocytes is observed in 24 hours, the smallest - on awakening. There is a relationship between the severity of the response of lymphoid cells to stimulation with phytohemagglutinin, the production of antibodies, immune globulins, and the time of day. Circadian periodicity in the circulation of T-helpers and T-cytotoxic suppressors, natural killers were established. Perhaps these fluctuations are associated with changes in the concentration of corticosteroids in the blood. The daily cycle of the immune response in humans (according to the skin sensitivity test to the antigen) is in antiphase to the rhythm of cortisol excretion in the urine. The highest level of antibodies and the severity of allergic reactions are noted during sleep and the minimum - in the awakestate. There is evidence that variations in the main populations of lymphoid cells, T and B lymphocytes, are in antiphase.

The following rhythmic changes of the immune system components and regulatory factors were established. (1) The maximum mitotic activity in the bone marrow and the content of stem hemopoietic cells at the beginning and minimum - in the middle of the light period. (2) In the morning, the colonization of peripheral organs with lymphocytes is much higher than in the evening. (3) In the first half of the day, there is a decrease in cellularity in the bone marrow, apparently due to migration of the corresponding cells from it.
(4) In the thymus, bone marrow, spleen, the greatest concentration of nucleic acids is observed in the morning and much less in the evening. (5) The maximum content of NK cells is observed in the middle of the dark period of the day. (6) The limiting phagocytic activity and the proliferative response to phytohemagglutinin were recorded in the morning, the minimum at night. (7) Maximum indicators of humoral immune response to ram erythrocytes and delayed type hypersensitivity were observed during immunization in the morning or afternoon. (8) In the evening, the thyroidstimulating hormone of the pituitary and thyroid hormones, which stimulate the function of the thymus, is increased. (9) The effect of immunotropes depends on the time of administration. (9a) Thus, hydrocortisone in the evening reduces the number of T-cytotoxic lymphocytes and increases $\mathrm{T}$-helpers, and in the morning does not affect T-cytotoxic lymphocytes. (9b) Injection of thymomimetics causes desynchronosis of biorhythms.

\section{Seasonal (circadian) rhythms of the immune system}

Less studied such fluctuations, caused by periodic changes in the environment and having, as a rule, geophysical nature.

It is significant that the nature of changes in the functioning of the immune system in children and adults differ among themselves.

Children. So, they have the maximum accumulation and activation of T-lymphocytes in the winter, an increase in the level of $\operatorname{IgG}, \operatorname{IgM}$, B-cells. In spring, there is a depression of the T-link of immunity (a drop in the number of T-cells, Thelpers, T-cytotoxic suppressors), while maintaining a sufficiently high concentration of $\operatorname{IgG}$ and decreasing the production of IgM and the number of B-lymphocytes. In summer, activation of T-cell defense mechanisms and the continued decline in production of $\operatorname{IgG}$ and B cells are noted. In autumn, further mobilization of all protective reactions is recorded, only a sharp decrease in the content of T-cytotoxic suppressors and continued monotonous inhibition of the formation of $\operatorname{IgM}$ and $\mathrm{IgG}$ does not fit into the general pattern. Thus, in the summer, autumn and winter, the oppression of some defense links is compensated by the activation of others. Only in the spring, the state of the immune system, with the exception of the IgG level, is suppressed in comparison with other periods. This, apparently, is due to a certain immaturity of the immune system in children.

Adults. In the autumn - there is a decrease in the level of Tcells, T-helpers, natural killers, the absorption and metabolic function of phagocytes, and in winter, on the contrary, the content of cytotoxic lymphocytes, NK cells, the magnitude of the phagocytic index decreases. In spring, the inhibition of cellular immunity by CD3 and CD8 lymphocytes is recorded, in the summer - activation of the T-cytotoxic suppressor link. The most pronounced circadian rhythms from July to September and minimal - from December to March. Biological rhythms are inert in the South and very pronounced in the North.

In the middle band of Russia in adults, humoral suppression occurs in the autumn, cellular immunity is activated, stimulation of T-and B-dependent protective reactions occurs in winter, activation of humoral (allergy) and suppression of cellular immunity in the spring, suppression of the main links of immunity in the summer against the background of the nonspecific factor activation of anti-infectious resistance - 
phagocytosis. Thus, the dynamics of immune parameters in adults seems figuratively speaking more "expedient" and "safe".

\section{CONCLUSION}

It is irrefutably shown that under the current conditions of the aggressive external environment, including traumatic effects of various medical therapeutic and diagnostic technologies, there are significant changes in immune reactivity, its biological rhythms, manifestations, and features, which causes a modification of the etiology, pathogenesis, and clinical course of infections that hamper their detection and treatment.

\section{References}

1. Zemskov AM, Esaulenko IE, Chereshnev VA, Zemskov VM, Suchkov SV, KozlovVA et al. Immunology. Electronic Textbook for Students of Medical Higher Education Institution and Faculties with Applications.Moscow. Publishing House: GEOTAR-media. 2016. 265 pages. Russia. http://www.studentlibrary.ru/ru/book/01-GEO201601.html

2. Vorobjev AA (Ed.) Medical Microbiology, Virology and Immunology. Moscow. Publishing House: Medical Information Agency. 2008. 720 p. Russia.

3. Vorobjev AA, Krivoshenin YuS, Shirobokov VP. Medical and sanitary microbiology. Tutorial. $4^{\text {th }}$ edition, stereotyped. Moscow. Publishing Center: Academy. 2010. 464 p. Russia.

4. Zemskov AM, Zemskov VM, Chereshnev VA (Ed.). Encyclopedia of Immunology in 5 volumes. Moscow. Publishing House: Triada-X.2013.1962 p. Russia.
5. Tsarev VN (Ed.). Microbiology, Virology and Immunology.Textbook for High Schools. Moscow. Publishing House: GEOTAR-media. 2010. 5436 p. Russia.

6. Zemskov AM, Zemskov VM, Zemskova VA, Zoloedov VI. Handbook of Clinical Immunologist "Theoretical, Practical and Applied Aspects of the Clinical Immunology at the Present Stage." Moscow. Publishing House: Triada-X. 2015. 704 p. Russia.

7. Labinskaya AS, Volina EG. (Ed.). Guide to medical microbiology. General and hygienic microbiology. Moscow. Publishing House: Binom. 2008. Book1. 1077p. Russia.

8. Novikov DK, Novikov PD. Clinical Immunopathology. Moscow. Publishing House: Medical Literature. 2009. 449 p. Russia.

9. Zemskov AM, Zemskov VM, Karaulov AV. Clinical Immunology.Textbook for Students of Medical Higher Education Institution. Moscow. Publishing House: GEOTAR-media. 2008. 426 p.Russia.

10. Pokrovskiy VI (Ed.). Manual for physicians clinical practice in clinical immunology, allergology, immunogenetics and immunopharmacology. Vol. 1 and 2. Moscow. 2005. 517 p. Russia.

11. PokrovskiyVI (Ed.). National concept of prevention of infections associated with the provision of medical care and information material on its provisions. N. Novgorod. PublishingHouse: Remedium Privolzjhe. 2012. 84 p. Russia.

12. Pokrovskiy VI, Pak SG, Briko NI. Infectious diseases and epidemiology. Textbook. 3rd edition, revised and enlarged. 2013. 1008 p.Russia.

13. Zemskov AM, Zemskov VM, Mamchik NP, Konovalov IM. Immuno-aggressive effect of environmental and hygienic factors. Moscow. Publishing House: Medicine. 2011.312 p. Russia.

\section{How to cite this article:}

AM Zemskov et al (2017) 'Immunology Of Infections At The Present Stage.Biological Rhythms Of Immune Reactivity', International Journal of Current Advanced Research, 06(05), pp. 3758-3762.

DOI: http://dx.doi.org/10.24327/ijcar.2017.3762.0363 